\title{
Investigation of Neptunium Precipitator Cleanout Options (U)
}

\author{
Benjamin C. Hill
}

June 2003

Westinghouse Savannah River Company Savannah River Site Aiken, SC 29808
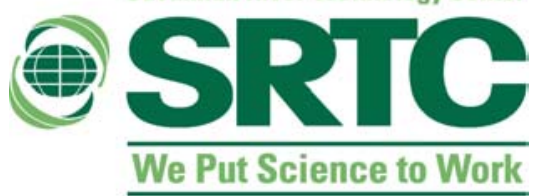

PREPARED FOR THE U. S. DEPARTMENT OF ENERGY UNDER CONTRACT NO. DE-AC09-96SR18500 
This document was prepared in conjunction with work accomplished under Contract No. DE-AC09-96SR18500 with the U. S. Department of Energy.

\section{DISCLAIMER}

This report was prepared as an account of work sponsored by an agency of the United States Government. Neither the United States Government nor any agency thereof, nor any of their employees, makes any warranty, express or implied, or assumes any legal liability or responsibility for the accuracy, completeness, or usefulness of any information, apparatus, product or process disclosed, or represents that its use would not infringe privately owned rights. Reference herein to any specific commercial product, process or service by trade name, trademark, manufacturer, or otherwise does not necessarily constitute or imply its endorsement, recommendation, or favoring by the United States Government or any agency thereof. The views and opinions of authors expressed herein do not necessarily state or reflect those of the United States Government or any agency thereof.

This report has been reproduced directly from the best available copy.

Available for sale to the public, in paper, from: U.S. Department of Commerce, National Technical Information Service, 5285 Port Royal Road, Springfield, VA 22161, phone: (800) 553-6847, fax: (703) 605-6900

email: orders@ntis.fedworld.gov

online ordering: http://www.ntis.gov/help/index.asp

Available electronically at http://www.osti.gov/bridge

Available for a processing fee to U.S. Department of Energy and its contractors, in paper, from: U.S. Department of Energy, Office of Scientific and Technical Information, P.O. Box 62, Oak Ridge, TN 37831-0062,

phone: (865)576-8401,

fax: (865)576-5728

email: $\underline{\text { reports@ adonis.osti.gov }}$ 


\section{Table of Contents}

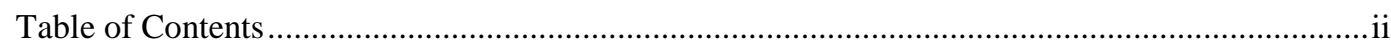

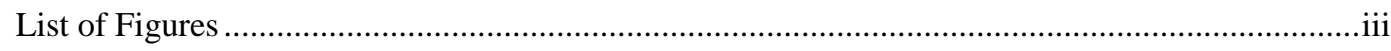

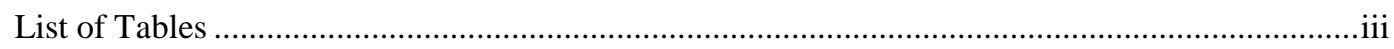

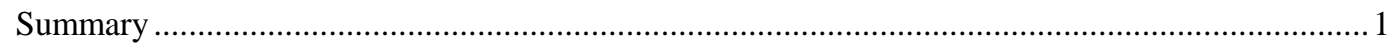

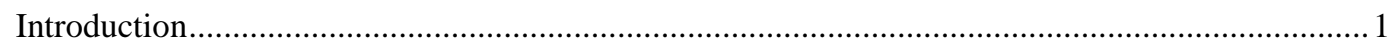

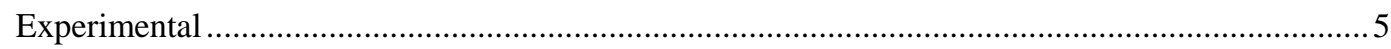

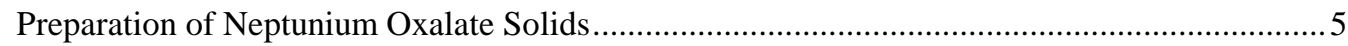

Measurement of Neptunium Concentration .........................................................................

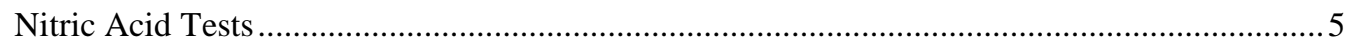

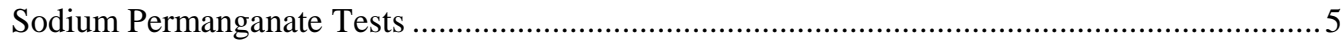

High Oxalic Acid, Low Nitric Acid Test ……………........................................................

Manganese Catalyzed Nitric Acid Reaction Test........................................................................

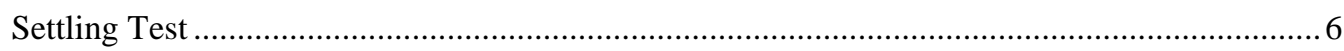

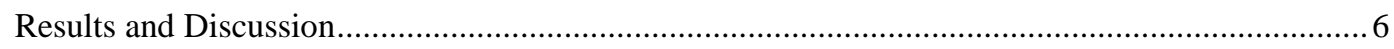

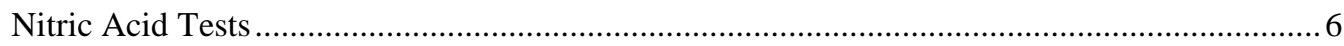

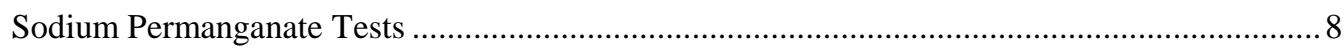

High Oxalic Acid, Low Nitric Acid Test ................................................................................

Manganese Catalyzed Nitric Acid Reaction Test.......................................................................

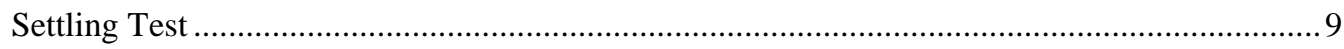

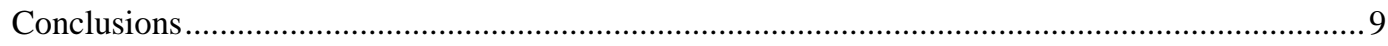

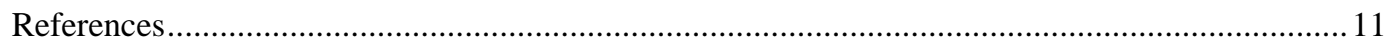




\section{List of Figures}

Figure 1. Neptunium oxalate solubility data and models (from Luerkens) .....................................2

Figure 2. Comparison of experimental data with Luerkens' models ............................................ 8

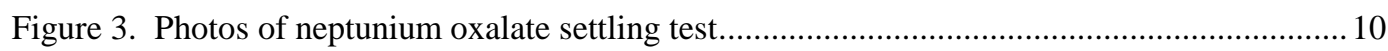

\section{List of Tables}

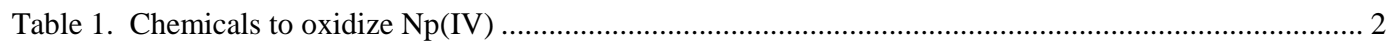

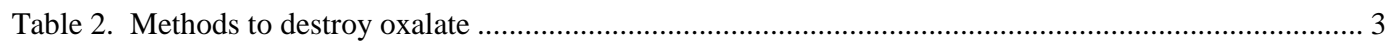

Table 3. Miscellaneous methods to improve neptunium oxalate solubility.................................................. 4

Table 4. Neptunium concentrations in nitric acid under various conditions .............................................. 6 
WSRC-TR-2003-00225

Revision 0

\section{Summary}

Oxalate precipitation followed by filtration is used in HB-Line Phase II to prepare plutonium oxalate. Historically, plutonium oxalate has tended to accumulate in the precipitation tanks. These solids are periodically removed by flushing with concentrated (64\%) nitric acid. The same precipitation tanks will now be used in the processing of neptunium. Literature values indicate that neptunium oxalate may not be as soluble as plutonium oxalate in nitric acid. ${ }^{1}$ HB-Line Engineering requested that the Actinide Technology Section (ATS) evaluate various methods to dissolve or suspend neptunium oxalate that may accumulate in the precipitator.

Although a wide variety of options is available to improve neptunium oxalate solubility for precipitator flushing, most of these options are not practical for use in the HB-Line facility. Many of these options require the use of incompatible or difficult to handle chemicals. Other options would require expensive equipment modifications or are likely to lead to product contamination. Based on review of literature and experimental results, the two best options for flushing the precipitator are 1) $64 \%$ nitric acid and 2) addition of sodium permanganate followed by sodium nitrite.

Nitric acid is the easiest option to implement. It is already used in the facility to flush plutonium oxalate out of the precipitator, so the need to change procedures, safety documentation, etc. is minimized. Another important advantage is that nitric acid will not lead to product contamination. Experimental results indicate that neptunium oxalate can be dissolved in concentrated nitric acid $(64 \%)$ at $60^{\circ} \mathrm{C}$ to a concentration of 2.6 to 5.6 grams of $\mathrm{Np} /$ liter after at least three hours of heating. A lower concentration ( 1.1 grams of $\mathrm{Np} /$ liter) was measured at $60^{\circ} \mathrm{C}$ after less than two hours of heating. These concentrations are acceptable for flushing if precipitator holdup is low ( 100-250 grams), but a second method is required for effective flushing if precipitator holdup is high ( 2 kilograms).

The most effective method for obtaining higher neptunium concentrations is the use of sodium permanganate followed by the addition of sodium nitrite. This method has been used successfully in the HB Line Phase II filtrate tank to destroy oxalate ions. Since this method is currently in use in HB Line, it is expected that implementation would not be difficult. However, there is concern that residual manganese from these flushes could impact product purity. Gas generation during permanganate addition is also a concern. Experimental results indicate that a solubility of at least 40 grams of Np/liter can be obtained using permanganate at ambient temperature, although it is expected that even higher neptunium concentrations can be achieved.

\section{Introduction}

Previous studies of neptunium oxalate solubility focused on minimizing solubility to reduce neptunium process losses during filtration. ${ }^{1}$ Figure 1 is a graph of the solubility models developed by Luerkens and the data used to generate those model. Rs* is defined as the solubility parameter and is equal to the molarity of oxalate ions in solution divided by the molarity of nitric acid squared. Although there is some physical basis for Luerkens' models, they are largely empirical and have only been verified for a range of conditions in which neptunium solubility is low. There is no reason to expect that these models would be valid outside of this range. Luerkens also took steps to ensure that neptunium remained in the +4 valence state. The valence state of neptunium may or may not remain at +4 during precipitator cleanout which can significantly affect neptunium oxalate solubility.

Although a wide variety of options are available for dissolving neptunium oxalate, many of these options are not practical for the HB-Line facility. There are several facility constraints that must be considered when evaluating an option. One of the primary concerns is product contamination. Any chemicals added should not contribute to product contamination. Another constraint is temperature. Equipment limitations prevent temperatures exceeding $60^{\circ} \mathrm{C}$, so dissolution methods that require higher temperatures cannot be used. Chemical incompatibility with process chemicals and tank corrosion must also be considered. Options that require extensive equipment modification are to be eliminated. These criteria reduce the possible options for neptunium oxalate dissolution to a relatively small set. A summary of several of the options considered is provided in this section. 
WSRC-TR-2003-00225

Revision 0

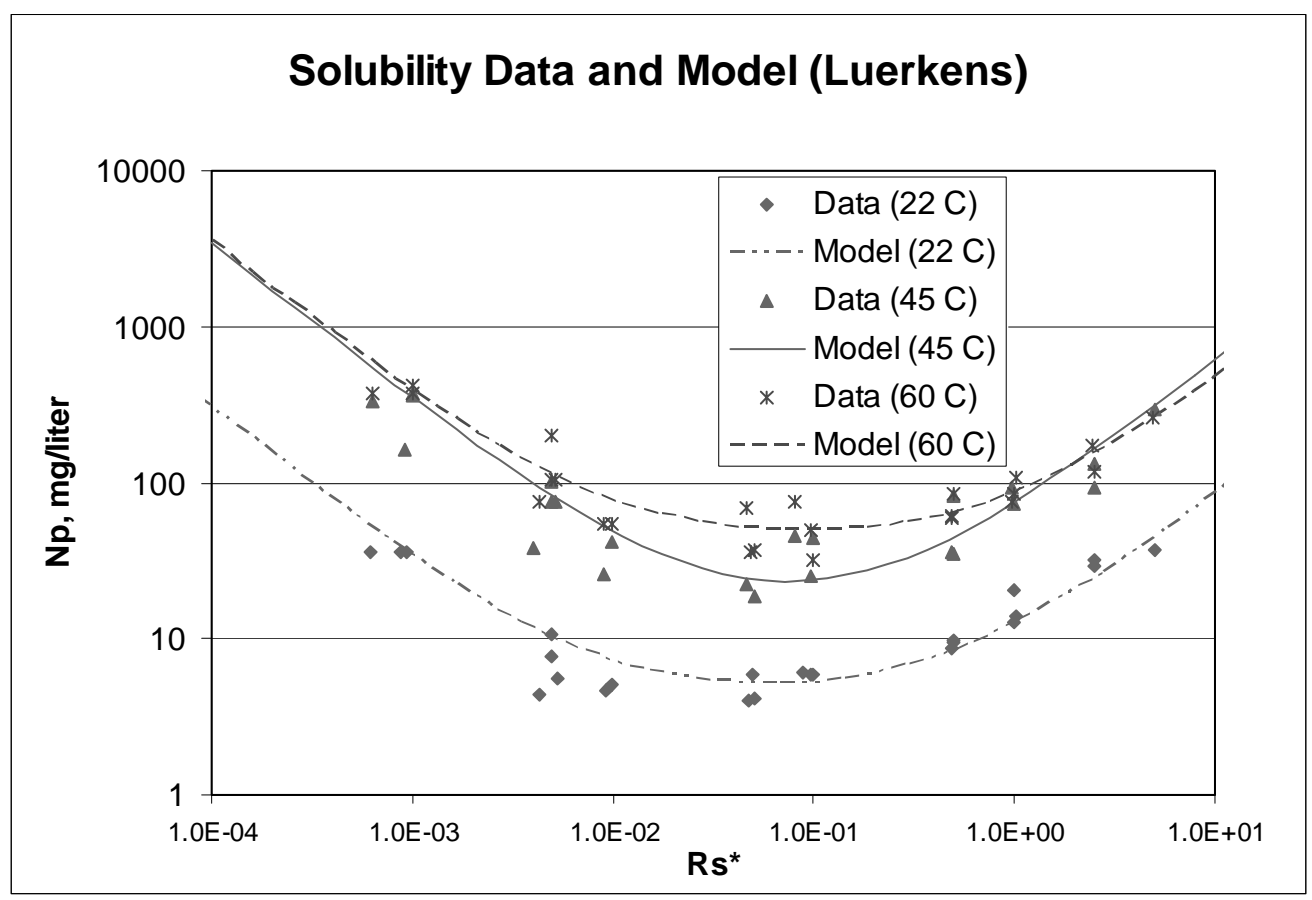

Figure 1. Neptunium oxalate solubility data and models (from Luerkens)

One possible mechanism for dissolving neptunium oxalate solids is oxidation of $N p(I V)$ to $N p(V)$ or $N p(V I)$. Because $N p(V)$ and $\mathrm{Np}(\mathrm{VI})$ do not form insoluble complexes with oxalate, oxidation of $\mathrm{Np}(\mathrm{IV})$ would be expected to increase solubility. There are a variety of compounds available to oxidize neptunium, but many are not acceptable for use in precipitator flushing. Table 1 contains some of the chemicals that could be used to oxidize Np (IV). It should be noted that literature information applies to neptunium in solution. The effectiveness of these oxidizers is expected to be reduced for solids.

Table 1. Chemicals to oxidize Np(IV)

\begin{tabular}{|l|l|l|l|l|}
\hline Chemical & Reaction & Advantages & Disadvantages & References \\
\hline $\mathrm{NO}_{3}{ }^{-}$in $\mathrm{HNO}_{3}$ & $\mathrm{~Np}(\mathrm{IV}) \Rightarrow \mathrm{Np}(\mathrm{V})$ & $\begin{array}{l}\text { Already in use in the facility; Easy to } \\
\text { implement }\end{array}$ & $\begin{array}{l}\text { Reaction is slow at ambient temperature and } \\
\text { faster at } 100^{\circ} \mathrm{C}\end{array}$ & 2,5 \\
\hline $\mathrm{Ag}(\mathrm{II})$ in $\mathrm{HClO}_{4}$ & $\mathrm{~Np}(\mathrm{IV}) \Rightarrow \mathrm{Np}(\mathrm{VI})$ & $\begin{array}{l}\text { Very fast reaction at ambient } \\
\text { temperature }\end{array}$ & $\begin{array}{l}\text { Possible formation of silver azide (shock } \\
\text { sensitive compound); Possible product } \\
\text { contamination }\end{array}$ & 2,5 \\
\hline $\mathrm{Ce}(\mathrm{IV})$ in $\mathrm{HNO}_{3}$ & $\mathrm{~Np}(\mathrm{IV}) \Rightarrow \mathrm{Np}(\mathrm{VI})$ & Fast reaction at ambient temperature & $\begin{array}{l}\text { Possible formation of cerium oxalate; } \\
\text { Possible product contamination }\end{array}$ & 2,5 \\
\hline $\mathrm{Cl}_{2}$ in $\mathrm{HCl}$ & $\mathrm{Np}(\mathrm{IV}) \Rightarrow \mathrm{Np}(\mathrm{V})$ & Fast reaction at $75^{\circ} \mathrm{C}$ & $\begin{array}{l}\text { Chlorine could lead to tank corrosion; } \\
\text { Equipment modifications required for gas } \\
\text { handling }\end{array}$ & 2,5 \\
\hline
\end{tabular}

Nitric acid is the only option in Table 2 that appears to be suitable for the HB-Line facility. Nitric acid has several advantages. It is readily available in the facility and it will not lead to product contamination. Unfortunately, this reaction is very slow at expected flushing temperatures (less than $60^{\circ} \mathrm{C}$ ). Another problem is that several competing reactions also take place which can return neptunium to the +4 valence state. At high acid concentration $\mathrm{Np}(\mathrm{V})$ disproportionates to form $\mathrm{Np}(\mathrm{IV})$ and $\mathrm{Np}(\mathrm{VI}):^{5}$

$$
2 \mathrm{NpO}_{2}^{+}+4 \mathrm{H}^{+} \leftrightarrow \mathrm{Np}^{4+}+\mathrm{NpO}_{2}^{2+}+2 \mathrm{H}_{2} \mathrm{O}
$$


The presence of nitrous acid, which is formed by the alpha-radiolysis of nitric acid solutions, also affects the valence state of neptunium. ${ }^{8}$ Nitrous acid oxidizes $\mathrm{Np}(\mathrm{IV})$ to $\mathrm{Np}(\mathrm{V})$ and reduces $\mathrm{Np}(\mathrm{VI})$ to $\mathrm{Np}(\mathrm{V})$. At low nitrous acid concentrations, nitrous acid can also act as a catalyst for the oxidation of $\mathrm{Np}(\mathrm{V})$ to $\mathrm{Np}(\mathrm{VI})$ by nitric acid. ${ }^{9,12}$ All of these competing reactions greatly complicate the nitric acid/neptunium oxalate system.

Another mechanism for dissolving neptunium oxalate solids is to destroy all of the oxalate ions. Table 2 summarizes a few of the possible methods to destroy oxalate. The methods listed in Table 2 may also oxidize Np(IV).

Table 2. Methods to destroy oxalate

\begin{tabular}{|l|l|l|l|}
\hline $\mathrm{Chemical}$ & Advantages & Disadvantages & References \\
\hline $\mathrm{NaMnO}_{4}$ & Available in facility & $\begin{array}{l}\text { Possible product contamination; gas } \\
\text { generation }\end{array}$ & $3,4,13$ \\
\hline $\begin{array}{l}\mathrm{HNO}_{3} \text { (with } \\
\mathrm{Mn} \text { (II) catalyst) }\end{array}$ & $\begin{array}{l}\text { Only a small amount of Mn(II) required } \\
\text { compared to using permanganate }\end{array}$ & $\begin{array}{l}\text { Slow reaction at ambient temperature but } \\
\text { faster at 90 }\end{array}$ & 3 \\
\hline $\mathrm{H}_{2} \mathrm{O}_{2}$ & No product contamination & $\begin{array}{l}\text { More effective when used with a UV light } \\
\text { (not practical) }\end{array}$ & 3,4 \\
\hline $\mathrm{O}_{3}$ & No product contamination & $\begin{array}{l}\text { Equipment modifications required for gas } \\
\text { handling; More effective at higher } \\
\text { temperatures (80 }\end{array}$ & 3,4 \\
\hline $\mathrm{Na}_{2} \mathrm{Cr}_{2} \mathrm{O}_{7}$ & $\begin{array}{l}\text { Chromium (VI) is toxic and a carcinogen; } \\
\text { May lead to product contamination }\end{array}$ & 3,4 \\
\hline
\end{tabular}

Sodium permanganate appears to be an attractive option. Sodium permanganate has been successfully used in the HB-Line facility to destroy oxalate ion in the filtrate tanks during plutonium processing. The major disadvantage is the possible contamination of the product by manganese oxide solids. Oxalate destruction can be accomplished by the addition of sodium permanganate to the precipitator. Sodium permanganate will also oxidize neptunium and any hydrazine or ascorbic acid, which may be present in the precipitator heel. The oxidation of oxalate, hydrazine, and ascorbic acid by the permanganate ion can be represented by the following equations: ${ }^{6,7}$

Partial reduction of permanganate:

$$
\begin{aligned}
& 2 \mathrm{MnO}_{4}^{-}+3 \mathrm{C}_{2} \mathrm{O}_{4}^{2-}+8 \mathrm{H}^{+} \rightarrow 2 \mathrm{MnO}_{2}+6 \mathrm{CO}_{2}+4 \mathrm{H}_{2} \mathrm{O} \\
& 20 \mathrm{MnO}_{4}^{-}+3 \mathrm{C}_{6} \mathrm{H}_{8} \mathrm{O}_{6}+20 \mathrm{H}^{+} \rightarrow 20 \mathrm{MnO}_{2}+18 \mathrm{CO}_{2}+22 \mathrm{H}_{2} \mathrm{O} \\
& 10 \mathrm{MnO}_{4}^{-}+6 \mathrm{~N}_{2} \mathrm{H}_{5}^{+}+4 \mathrm{H}^{+} \rightarrow 10 \mathrm{MnO}_{2}+3 \mathrm{~N}_{2} \mathrm{O}+3 \mathrm{~N}_{2}+17 \mathrm{H}_{2} \mathrm{O}
\end{aligned}
$$

Complete reduction of permanganate:

$$
\begin{aligned}
& 2 \mathrm{MnO}_{4}^{-}+5 \mathrm{C}_{2} \mathrm{O}_{4}^{2-}+16 \mathrm{H}^{+} \rightarrow 2 \mathrm{Mn}^{2+}+10 \mathrm{CO}_{2}+8 \mathrm{H}_{2} \mathrm{O} \\
& 4 \mathrm{MnO}_{4}^{-}+\mathrm{C}_{6} \mathrm{H}_{8} \mathrm{O}_{6}+12 \mathrm{H}^{+} \rightarrow 4 \mathrm{Mn}^{2+}+6 \mathrm{CO}_{2}+10 \mathrm{H}_{2} \mathrm{O} \\
& 2 \mathrm{MnO}_{4}^{-}+2 \mathrm{~N}_{2} \mathrm{H}_{5}^{+}+4 \mathrm{H}^{+} \rightarrow 2 \mathrm{Mn}^{2+}+\mathrm{N}_{2} \mathrm{O}+\mathrm{N}_{2}+7 \mathrm{H}_{2} \mathrm{O}
\end{aligned}
$$


WSRC-TR-2003-00225

Revision 0

Any manganese oxide solids that are formed can be dissolved by the addition of sodium nitrite. The equation for the reaction of manganese dioxide and nitrite is:

$$
\mathrm{MnO}_{2}+\mathrm{NO}_{2}^{-}+2 \mathrm{H}^{+} \rightarrow \mathrm{Mn}^{2+}+\mathrm{NO}_{3}^{-}+\mathrm{H}_{2} \mathrm{O}
$$

Competing with the reduction of manganese oxide is the loss of nitrite in acidic solution. High acid or nitrite concentration will increase this loss.

$$
2 \mathrm{NO}_{2}^{-}+2 \mathrm{H}^{+} \rightarrow \mathrm{H}_{2} \mathrm{O}+\mathrm{NO}+\mathrm{NO}_{2}
$$

The use of nitric acid with a manganese catalyst may be preferable over the use of sodium permanganate due to the very small quantity of manganese that would be required reducing the potential for product contamination. Also, this method is not expected to produce manganese oxide solids. Previous work has analyzed this reaction, but focused on higher temperatures (over $90^{\circ} \mathrm{C}$ ). ${ }^{3,11}$ A major concern is that the reaction may occur too slowly at precipitator temperatures $\left(60^{\circ} \mathrm{C}\right.$ or less) to be effective. This reaction tends to be more effective at lower nitric acid concentrations; however, enough nitric acid must be present to react with the oxalate ions., ${ }^{3,10}$

Peroxide is another attractive option, since its use will not lead to product contamination, but it may react too slowly to be of use. Previous studies have shown that destruction of oxalate using peroxide with an ultraviolet (UV) light is very effective. ${ }^{4}$ Use of a UV light in the precipitator is not practical. Without UV light, the use of peroxide has been shown to be less effective at destroying oxalate than the previously mentioned manganese-catalyzed nitric acid reaction. ${ }^{3}$

Ozone effectively destroys oxalate ions and will not lead to product impurities. ${ }^{3,4}$ However, the use of ozone would require equipment modification for ozone generation and addition of a gas to the precipitator. Ozone also tends to be more effective at higher temperatures.

Sodium dichromate does not appear to be suitable for precipitator flushing. Sodium dichromate is toxic and a carcinogen. Use of sodium dichromate may also lead to product contamination.

There were some methods of increasing neptunium oxalate solubility found in literature that did not fit into the previously discussed categories. These methods are summarized in Table 3.

Table 3. Miscellaneous methods to improve neptunium oxalate solubility

\begin{tabular}{|l|l|l|l|}
\hline Solution description & Advantages & Disadvantages & References \\
\hline $\begin{array}{l}\text { Low nitric acid; High oxalic } \\
\text { acid }\end{array}$ & No product contamination & Effectiveness is unknown & 1 \\
\hline Dilute carbonate solution & $\begin{array}{l}\text { Low potential for product } \\
\text { contamination }\end{array}$ & Basic solution & 2 \\
\hline
\end{tabular}

Luerkens indicated that a high oxalate concentration in low nitric acid encourages the formation of a more soluble neptunium oxalate complex $\left(\mathrm{Np}\left(\mathrm{C}_{2} \mathrm{O}_{4}\right)^{2+}\right) .{ }^{1}$ This increasing solubility in the oxalic-rich region can be seen in Figure 1. As Rs* increases above approximately 0.2 , the solubility of neptunium oxalate increases. Unfortunately, no data are available for higher oxalate concentrations of interest (Rs*>10) to support the model predictions.

Literature indicates that neptunium oxalate is soluble in dilute carbonate solutions. ${ }^{2}$ Literature speculates that carbonate ions will replace oxalate to form soluble neptunium carbonate complexes. Very few details (concentrations, conditions, etc.) are provided, so it is unclear whether or not this method would be effective. One major disadvantage is that this method requires the introduction of a basic solution to the HB-Line facility which is incompatible with nitric acid. Vigorous off gassing of $\mathrm{CO}_{2}$ would occur. 
WSRC-TR-2003-00225

Revision 0

\section{Experimental}

\section{Preparation of Neptunium Oxalate}

Neptunium oxalate solids were precipitated from neptunium solutions that had previously been purified by anion exchange. The entire precipitation was carried out at ambient temperature. The feed solution was adjusted to $4 \mathrm{M}$ nitric acid and $0.05 \mathrm{M}$ ascorbic acid prior to precipitation. The feed was then made $0.05 \mathrm{M}$ in hydrazine to maintain the neptunium in the +4 valence state. A sufficient volume of oxalic acid $(0.9 \mathrm{M})$ was added to precipitate the neptunium and to provide a $0.1 \mathrm{M}$ excess of oxalic acid.

\section{Measurement of Neptunium Concentration}

Neptunium concentrations were measured by the Analytical Development Section (ADS) of the Savannah River Technology Center. An aliquot of each sample was diluted to an appropriate activity level using dilute nitric acid and analyzed by gamma spectroscopy analysis using a high purity germanium detector. Alpha counting was also performed by ADS to validate gamma results. An aliquot of each sample was diluted to an appropriate activity level using dilute nitric acid and mounted on a stainless steel counting planchet. The planchet was then counted using both a proportional counter (for gross alpha value) and alpha spectroscopy instrumentation (for pulse height analyses). Reported neptunium concentrations are values obtained by gamma PHA unless otherwise noted.

\section{$\underline{\text { Nitric Acid Tests }}$}

Several tests were performed under various conditions to evaluate the effectiveness of nitric acid in dissolving neptunium oxalate solids. In all of these tests, the neptunium oxalate from precipitation was filtered and the filtrate cake was rinsed using a $2 \mathrm{M}$ nitric acid $0.1 \mathrm{M}$ oxalic acid solution. The rinsed solids were then added to nitric acid. Several standard nitric acid concentrations $(41 \%, 64 \%$, and $69 \%)$ were used, but most tests focused on $64 \%$ nitric acid. Various temperatures, stirring rates, and contact times were also tested. Samples were taken and analyzed to determine neptunium concentration.

\section{$\underline{\text { Sodium Permanganate Tests }}$}

After precipitation, the neptunium oxalate solids were allowed to settle and most of the solution was decanted. Rinse solution $\left(2 \mathrm{M} \mathrm{HNO}_{3}\right.$ and $0.1 \mathrm{M}$ oxalic acid) was added to the solids and then decanted. Nitric acid (4M) was added to the solids followed by the addition of $4 \mathrm{M}$ sodium permanganate. Sodium nitrite was then added to dissolve any manganese oxide solids. Two tests were performed using sodium permanganate:

Test 1 - Sodium permanganate and sodium nitrite were added to the solution at ambient temperature and a sample was taken.

Test 2 - Sodium permanganate and sodium nitrite were added to the solution at approximately $60^{\circ} \mathrm{C}$. The solution was allowed to cool and a sample was taken at ambient temperature.

\section{High Oxalic Acid, Low Nitric Acid Test}

Neptunium oxalate solids were filtered from the precipitate slurry. The filtrate cake was rinsed using a $2 \mathrm{M}$ nitric acid $0.1 \mathrm{M}$ oxalic acid solution. These solids were added to a high oxalic acid $(0.5 \mathrm{M})$ and low nitric acid $(0.1 \mathrm{M})$ solution. A sample was taken at ambient temperature.

\section{$\underline{\text { Manganese Catalyzed Nitric Acid Reaction Test }}$}

Neptunium oxalate solids were filtered and rinsed. Neptunium oxalate was then heated at approximately $60^{\circ} \mathrm{C}$ for 9.5 hours in a nitric acid $(0.6 \mathrm{M})$ and manganous nitrate $(0.2 \mathrm{M})$ solution. A sample of the solution was taken at $60^{\circ} \mathrm{C}(0.1 \mathrm{ml}$ sample into 
$1 \mathrm{ml} 15.8 \mathrm{M} \mathrm{HNO}_{3}$ ). The solution was allowed to cool back to ambient temperature over approximately 24 hours and then another sample was taken.

\section{$\underline{\text { Settling Test }}$}

There is some concern that as neptunium oxalate solids remain in the precipitator for several weeks that these solids may be more difficult to suspend/dissolve due to consolidation of particles. It was difficult to perform any quantitative testing, so a simple qualitative test was performed to evaluate this scenario. Neptunium oxalate solids were precipitated using the previously described method. The solids were allowed to settle in a vial for 10 weeks. The solids were then suspended by swirling the vial. Observations were recorded and photos were taken during the suspension of the solids. Careful attention was paid to any evidence of caking or agglomeration of the solid particles.

\section{Results and Discussion}

\section{Nitric Acid Tests}

Three tests (1A, 2A, and 3A) were performed in which solubility of neptunium oxalate was tested by maintaining acid and neptunium oxalate at temperatures of $22^{\circ} \mathrm{C}, 45^{\circ} \mathrm{C}$, and $60^{\circ} \mathrm{C}$ for approximately two hours with very little mixing. The variable for these tests was nitric acid concentration. Measured neptunium concentrations ranged from 1.5 to $8.9 \mathrm{~g} /$ liter. Results are shown in Table 4. Another sample was taken after solutions were allowed to cool overnight. Notice in Table 4 that for the first three tests $(1 \mathrm{~A}, 2 \mathrm{~A}$, and $3 \mathrm{~A})$ the concentrations after cooling were greater than the initial concentrations at ambient temperature. These higher concentrations suggest oxidation of $\mathrm{Np}(\mathrm{IV})$ by nitric acid to the more soluble $\mathrm{Np}(\mathrm{V})$ and $\mathrm{Np}(\mathrm{VI})$ or destruction of oxalate.

Table 4. Neptunium concentrations in nitric acid under various conditions

\begin{tabular}{|c|c|c|c|c|c|}
\hline \multirow[t]{2}{*}{ Test ID } & \multirow{2}{*}{$\begin{array}{l}\text { Nitric acid } \\
\text { concentration, } \\
\text { weight } \%\end{array}$} & \multicolumn{4}{|c|}{ Neptunium concentration, grams/liter } \\
\hline & & $22^{\circ} \mathrm{C}$ & $45^{\circ} \mathrm{C}$ & $60^{\circ} \mathrm{C}$ & $22^{\circ} \mathrm{C}$ (after cooling) \\
\hline $1 \mathrm{~A}$ & 41 & 1.5 & 2.8 & 4.6 & 2.9 \\
\hline $2 \mathrm{~B}$ & 64 & - & - & 4.4 & - \\
\hline $2 \mathrm{C}$ & 64 & - & - & 1.1 & - \\
\hline $2 \mathrm{D}$ & 64 & - & - & 2.6 & 1.1 \\
\hline $3 \mathrm{~A}$ & 69 & 4.7 & 6.9 & 8.9 & 7.1 \\
\hline
\end{tabular}

* Results are based on alpha counting. Gamma PHA results were not available.

Two additional tests (2B and $2 \mathrm{C}$ ) were run using $64 \%$ nitric acid. In Test $2 \mathrm{~B}$ the neptunium oxalate solids were heated $\left(\sim 60^{\circ} \mathrm{C}\right)$ in nitric acid for over three hours with significantly more mixing than previous tests $(1 \mathrm{~A}, 2 \mathrm{~A}$, and $3 \mathrm{~A})$. A concentration of 4.4 grams of $\mathrm{Np} / \mathrm{liter}$ was measured. When the solution was heated for slightly less than two hours during Test $2 \mathrm{C}$, the neptunium concentration was only 1.1 grams/liter.

An additional experiment (2D) was performed with a longer heating time (9.5 hours) with the expectation that longer heating time might result in additional oxidation of neptunium which would be expected to increase solubility. After almost 10 hours of heating neptunium oxalate solids in nitric acid, the neptunium concentration was only 2.6 grams/liter at $60^{\circ} \mathrm{C}$ and 1.1 grams/liter after cooling. These results indicate that increased heating time does not increase solubility. One possible explanation for this phenomenon is the generation of nitrous acid over time by the alpha radiolysis of nitric acid. Nitrous acid can reduce $\mathrm{Np}(\mathrm{VI})$ to $\mathrm{Np}(\mathrm{V})$ which would then be expected to disproportionate into $\mathrm{Np}(\mathrm{IV})$ and $\mathrm{Np}(\mathrm{VI})$ in concentrated nitric acid. It is difficult to verify this explanation without any actual information on the valence state of neptunium. 
Due to the variability of previous results, an additional 64\% nitric acid test was performed (2E). Enough neptunium ( 0.1 grams) was added to $21 \mathrm{ml}$ of nitric acid so that if all of the neptunium dissolved the concentration would be approximately 5 grams/liter. All of the neptunium dissolved quickly at room temperature. Analytical results indicated a neptunium concentration of 5.6 grams/liter at $60^{\circ} \mathrm{C}$. A sample was taken approximately 24 hours later after the solution was allowed to cool and the measured concentration was once again 5.6 grams of Np/liter. There was a very small amount of solids (barely visible) noted in the bottom of the vial. The vial was observed for seven days with no significant change in the amount of solids present. The high concentration observed at room temperature during this test was somewhat surprising. The only major difference between this test and the other tests using $64 \%$ nitric acid was that the ratio of neptunium solids to acid volume was much lower in this test. In other tests a surplus of neptunium was added in an attempt to determine the maximum solubility. In Test $2 \mathrm{E}$ only the amount of neptunium that was expected to dissolve was added.

In all of the $64 \%$ and $69 \%$ nitric acid tests, the solutions had a slight pink/brown color. $\mathrm{Np}(\mathrm{VI})$ ions in solutions $\left(\mathrm{NpO}_{2}\left(\mathrm{H}_{2} \mathrm{O}\right)_{6}{ }^{2+}\right)$ are known to have a pink color ${ }^{2}$; however, this observation is not a definitive indicator that $\mathrm{Np}(\mathrm{VI})$ was present because neptunium nitrate complexes may also have been present which could have affected the color of the solution. ${ }^{5}$ It is not expected that $\mathrm{Np}(\mathrm{V})$ would be present for long in concentrated nitric acid. $\mathrm{Np}(\mathrm{V})$ has a higher tendency to disproportionate into $\mathrm{Np}(\mathrm{IV})$ and $\mathrm{Np}(\mathrm{VI})$ as acid concentration increases. ${ }^{5}$

As described previously, the measured concentration of neptunium in $64 \%$ nitric acid varied considerably. Due to the complexity of the nitric acid/nitrous acid/neptunium oxalate system, it is difficult to isolate the source of the variability. There are several possible sources for the scatter in the results. Small amounts of nitrous acid can significantly influence neptunium valence. There were variations in the temperature and the heating time. Several competing reactions are expected to take place which can either oxidize or reduce neptunium. Without direct information on the valence state of neptunium it is difficult to determine which reactions are important.

Experimental results were compared to previous data and models in Figure 2. The model tended to under predict the concentration of neptunium in the oxalate-lean region (low Rs*). This result is not surprising because the data used to develop the model do not cover this region. Also Luerkens maintained neptunium in the +4 valence state. Oxidation of neptunium is expected to increase solubility. There was only one case in the oxalate-lean region where concentration was greatly over predicted by Luerkens' model. In Test $2 \mathrm{C}$ a low neptunium concentration $(1.1 \mathrm{~g} /$ liter) was measured in $64 \%$ nitric acid at $60^{\circ} \mathrm{C}$. The difference between this test and the other nitric acid tests was the relatively low contact time $(<$ two hours) with nitric acid. During other tests the neptunium oxalate solids were in contact with nitric acid for more that three hours prior to sampling. The nitric acid solution in Test $2 \mathrm{C}$ may not have had time to reach equilibrium with the solids before sampling.

A higher neptunium concentration ( 9 grams $\mathrm{Np} /$ liter) was achieved by heating neptunium oxalate $\left(60^{\circ} \mathrm{C}\right.$ for approximately three hours) in 64\% nitric acid, allowing the solution to sit overnight, decanting most of the acid, and then diluting the remaining solution with water to an acid concentration of approximately $5 \mathrm{M}$ (Test 4A). This method was also effective in a similar experiment (Test $4 \mathrm{~B}$ ) where the solution was diluted to approximately $2 \mathrm{M}$ nitric acid. One theory explaining the increased concentrations observed in Test $4 \mathrm{~A}$ and $4 \mathrm{~B}$ is that exposure to concentrated nitric acid oxidized a portion of the $\mathrm{Np}(\mathrm{IV})$ to $\mathrm{Np}(\mathrm{VI})$. Once the acid was diluted, $\mathrm{Np}(\mathrm{IV})$ reacted with $\mathrm{Np}(\mathrm{VI})$ to form $\mathrm{Np}(\mathrm{V})$ via the reverse of the disproportionation reaction (Reaction 1). More neptunium would be expected to dissolve, because $\mathrm{Np}(\mathrm{V})$ and $\mathrm{Np}(\mathrm{VI})$ do not form insoluble complexes with oxalate. A follow up experiment (Test 4C) was conducted to determine if the pretreatment with concentrated nitric acid used in Test $4 \mathrm{~A}$ and Test $4 \mathrm{~B}$ is actually required. Neptunium oxalate did not appreciably dissolve in $2 \mathrm{M}$ nitric acid even with heating, indicating that the pretreatment does significantly affect the final concentration. Although these results are interesting, use of the method applied in Test 4A and Test 4B is undesirable due to its complexity, a limited understanding of its mechanism, and the amount of time required for dissolution. Based on these considerations, no further studies of this method were performed. 

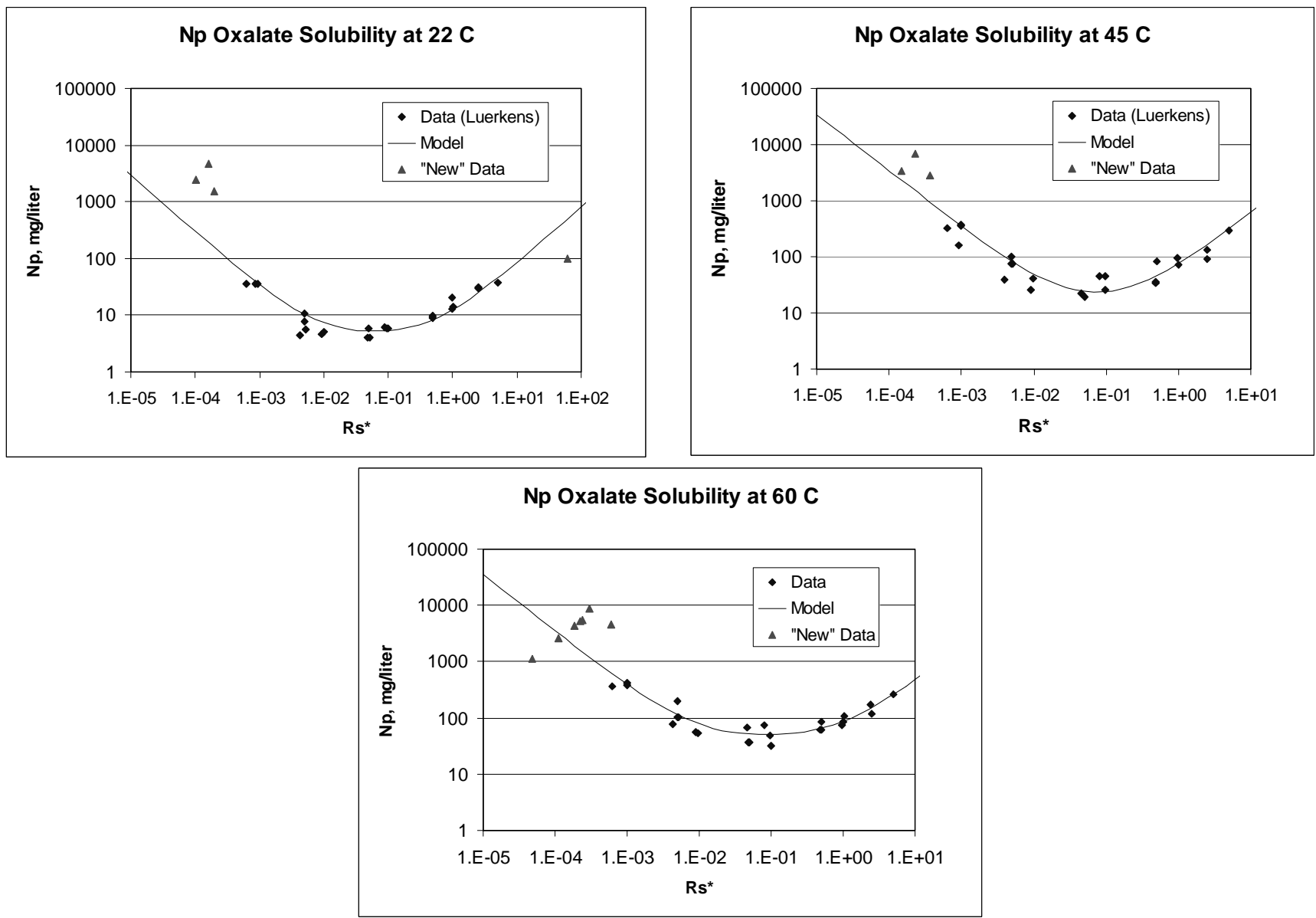

Figure 2. Comparison of experimental data with Luerkens' models

\section{$\underline{\text { Sodium Permanganate Tests }}$}

During Test 1 (ambient temperature), an attempt was made to minimize the disturbance of the settled solids during permanganate addition. The solids were allowed to sit in permanganate for approximately five hours. At the end of this time a significant portion (roughly 25-50\%) of the solids was still on the bottom of the vial. A stir bar was added to the vial and the solids were stirred for approximately two hours. Sodium nitrite was added to destroy any manganese oxide solids. All of the solids dissolved and a concentration of 27.5 grams of Np/liter was measured. There was no significant foaming or gassing during the permanganate addition. The reaction of permanganate with oxalate appeared to be fairly slow. Most likely the reaction was limited by the dissolution rate of the oxalate ions. It is expected that elevating the temperature will increase the dissolution and reaction rates.

Test 2 was performed at $60^{\circ} \mathrm{C}$ to verify that the dissolution/reaction rate will be increased, to verify that higher neptunium concentrations can be achieved, and to check for any problems associated with heating (excessive gas generation rate). All of the solids dissolved when the nitrite was added. A neptunium concentration of 40 grams/liter at ambient temperature was measured, but it is expected that even higher concentrations can be obtained. An increased amount of foaming (1-2 inches of foam) was observed during this test. This gas generation is of concern because it could lead to tank over pressurization or eructation. It should be noted that the permanganate addition rate was much faster (all of the permanganate was added in less than two minutes) than what is expected for use in the HB-Line facility. 
WSRC-TR-2003-00225

Revision 0

\section{High Oxalic Acid, Low Nitric Acid Test}

The measured neptunium concentration at ambient temperature was only 0.1 grams/liter. This concentration is lower than what Luerkens' model predicts ( 0.5 grams of $\mathrm{Np} /$ liter) for this set of conditions (see Figure 1$)$. This is not surprising because the solubility factor is well outside of the range of data that Luerkens used to develop his models. This method is not useful for flushing the precipitator.

\section{Manganese Catalyzed Nitric Acid Reaction Test}

Concentrations of 2.1 and 2.3 grams of $\mathrm{Np} /$ liter were measured at $60^{\circ} \mathrm{C}$ and ambient temperature, respectively. The higher concentration at room temperature indicates that the reaction continued to occur overnight as the solution cooled. At a nitric acid concentration of $0.6 \mathrm{M}$ and assuming 2 moles of oxalate per mole of neptunium, Luerkens models predict neptunium concentrations of 0.04 and 0.16 grams $\mathrm{Np} / \mathrm{liter}$ at $22^{\circ} \mathrm{C}$ and $60^{\circ} \mathrm{C}$, respectively. The concentrations obtain using manganese with the same nitric acid concentration were much higher. These results indicate that oxalate was destroyed and/or neptunium was oxidized by nitric acid with the manganese catalyst. Given more heating time or higher temperature the use of a nitric acid with a manganese catalyst appears to be an effective option. Unfortunately, due to current equipment and operating constraints the use of this method does not appear to be practical.

\section{$\underline{\text { Settling Test }}$}

After the vial was swirled a few times, it was noted the solids were all suspended with little effort. Figure 3 contains photos of the vial at various stages of mixing. Once suspended, the solids settled slowly to the bottom indicating small particle sizes. There was no evidence of agglomeration of particles. Based on visual observations, there was very little difference between suspending solids that settled for 2-3 days and those that settled for 10 weeks. Solids that were allowed to settle for 2-3 days had slightly more interstitial water and were slightly easier to suspend. Based on visual observations, it may be possible to suspend solids during flushing which would be expected to increase the dissolution rate and to allow removal of neptunium solids during the flush.

\section{Conclusions}

Although a wide variety of options are available for dissolving neptunium oxalate solids, most of these options can be eliminated due to processing and equipment constraints. Nitric acid and permanganate were the only two options evaluated that are practical for flushing the precipitator.

Nitric acid (64\%) is only effective for very small precipitator holdup, but it does have the advantage of no product contamination. Measured neptunium concentrations were between 2.6 and 5.6 grams/liter at $60^{\circ} \mathrm{C}$ for contact times greater than three hours. Based on these results small amounts of neptunium oxalate can be removed from the precipitator using nitric acid. Assuming a flush volume of 50 liters, it is expected that 100-250 grams of neptunium can be removed in a single flush. It is possible that larger quantities can be removed if the agitator is able to suspend some of the neptunium oxalate solids.

Sodium permanganate is a very effective way to dissolve larger amounts neptunium oxalate. Measured concentrations were as high as 40 grams Np/liter but it is expected that higher concentrations can be achieved. Assuming a flush volume of 50 liters, permanganate is capable of removing at least two kilograms of neptunium in a single flush. It should be noted that additional flushes may be required to ensure manganese solids have been removed from the precipitator. There are two significant disadvantages to the use of permanganate: 1) use of permanganate in the precipitator could lead to product contamination and 2) gas is generated by the reaction of permanganate with oxalate. The addition rate of permanganate will need to be controlled to prevent eructation or tank over pressurization. 


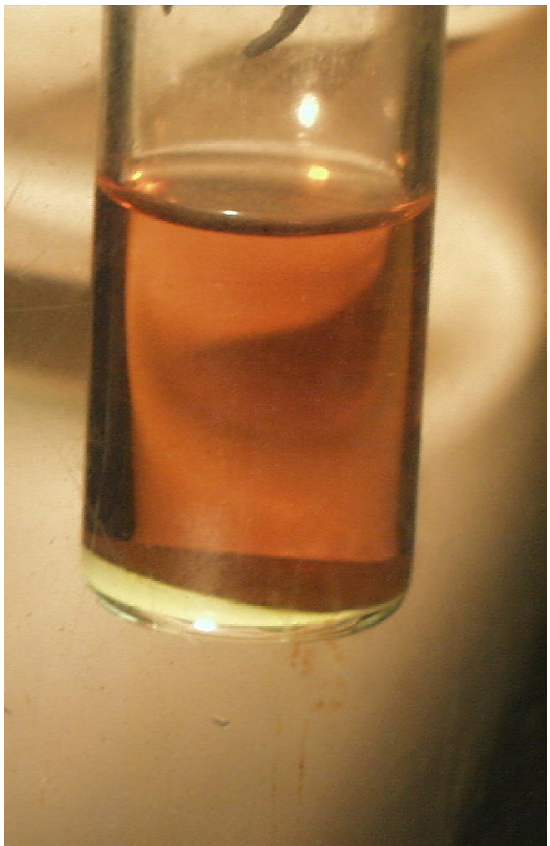

1) Undisturbed neptunium solids; the color of the solution is due to ascorbic acid

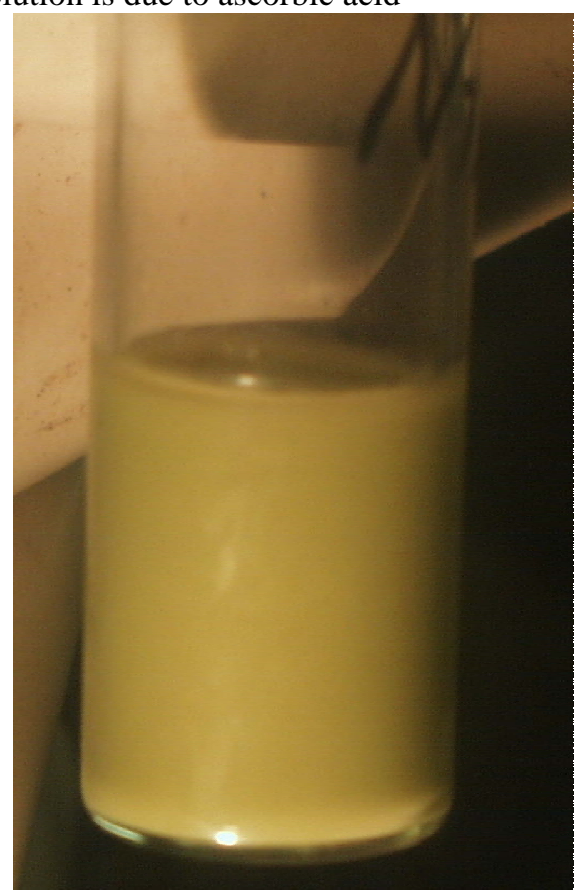

3) Np solids after more vigorous swirling of the vial; all solids were suspended

Figure 3. Photos of neptunium oxalate settling test

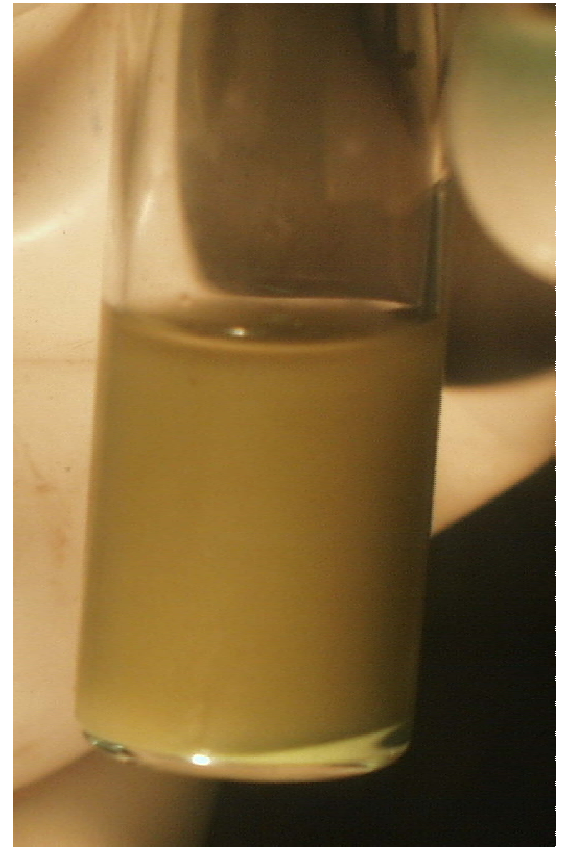

2) Np solids after gentle swirling of vial

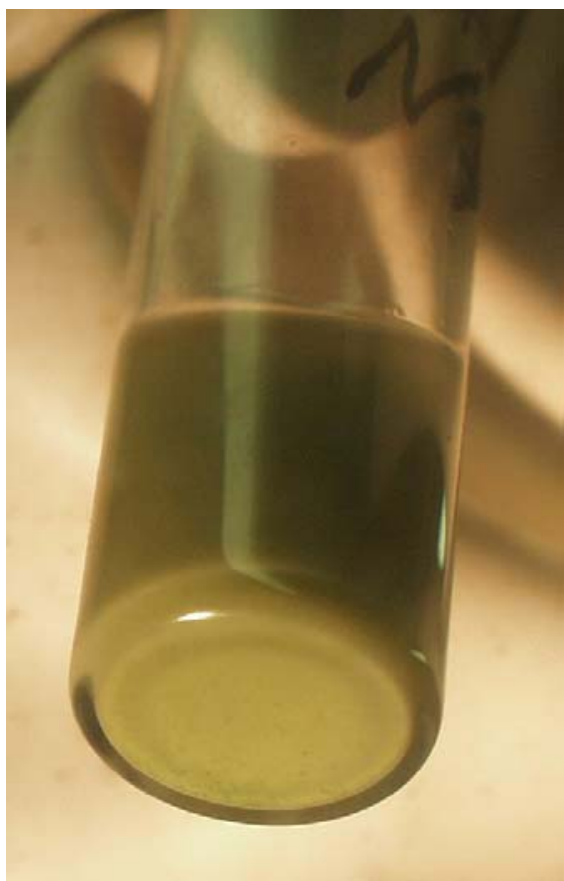

4) Same as previous photo but at a different angle 
WSRC-TR-2003-00225

Revision 0

\section{References}

1. D. W. Luerkens, Neptunium (IV) Oxalate Solubility, Report No. DP-1655, E. I. du Pont de Nemours and Co., Aiken, SC (1983).

2. G. A. Burney and R. M. Harbour, Radiochemistry of Neptunium, Report No. NAS-NS-3060, United States Atomic Energy Commission Technical Information Center, Oak Ridge, TN (1974).

3. N. E. Bibler, Technical Data Summary Decomposition of Oxalic Acid by the Manganese Catalyzed Nitric Acid Reaction, Report No. DPSTD-80-36, E. I. du Pont de Nemours and Co., Aiken, SC (1981).

4. F. T. Wang and B. Y. Lum, Photolytic Destruction of Oxalate in Aqueous Mixed Waste, Report No. UCRL-JC-119739, Lawrence Livermore National Laboratory, Livermore, CA (1995).

5. J. J. Katz, G. T. Seaborg, and L. R. Morss, The Chemistry of the Actinide Elements Second Edition: Volume 1, Chapman and Hall, New York, NY (1986).

6. J. H. Gray, The Formation and Dissolution of Plutonium Oxalate Solids in HB-Line Phase II Filtrate Streams, WSRCTR-2001-00317, (2001).

7. J. W. Ladbury and C. F. Cullis, "Kinetics and Mechanism of Oxidation by Permanganate", Chemical Reviews, 58, 403, (1959).

8. N. N. Adreichuk, K. V. Rotmanov, A. A. Frolov, and V. Ya. Vasil'ev, "Effect of Alpha-Irradiation on the Valence States of Actinides. IV. Kinetics of $\mathrm{HNO}_{2}$ Formation in Nitric Acid Solutions", Radiokhimiya, Vol. 26, No. 6, (1984).

9. T. H. Siddall and E. K. Dukes, "Kinetics of HNO2 Catalyzed Oxidation of Neptunium(V) by Aqueous Solutions of Nitric Acid", J. Am. Chem. Soc., 81, 790 (1959).

10. J. H. Radke to E. S. Bridges, Inter-Office Memorandum, Oxidation of Oxalic and Ascorbic Acids by Nitric Acid, (1978).

11. V. S. Koltunov, "The Kinetics and Mechanism of Oxalic Acid Oxidation by Nitric Acid in the Presence of Divalent Manganese Ions", translated from Kinetika i Kataliz, Vol. 9, No. 5, pp. 1034-1041 (1968).

12. S. Homma, "An Approach for Evaluating Equilibrium and Rate Constants for the Reaction of $\mathrm{Np}(\mathrm{V})$ with Nitric Acid in the Purex Process Using Process Data", Nuclear Technology, Vol. 116, (1996).

13. B. C. Hill and M. G. Bronikowski, Gas Generation during Sodium Permanganate Addition to HB-Line Phase II Filtrate Tank, Report No. WSRC-TR-2002-00350, (2002). 